\title{
GOLD ALLOY METAL CLIPS VERSUS NYLON PLASTIC CLIPS OF STRESS-FREE IMPLANT (SFI) BAR USED FOR IMMEDIATELY LOADED 4-IMPLANT ASSISTED MANDIBULAR OVERDENTURES. ONE-YEAR RANDOMIZED CLINICAL TRIAL
}

\author{
Waleed Hamed Maryod*, Engy Ali Abdelhaleem Salam*** and Ghada Ahmed Alkaranfilly***
}

\begin{abstract}
Purpose: The aim of this randomized trial was to evaluate marginal bone loss and patient satisfaction with gold alloy metal clips versus nylon plastic clips of stress-free implant (SFI) bar used for immediately loaded 4-implant assisted mandibular overdentures.

Materials and methods: Eight edentulous patients with unsatisfactory experience of retention and stability of mandibular conventional dentures, but had adequate bone volume anterior and posterior to the mental foramina received 4 implants in canines and first molar areas of the mandible. Implant were connected with SFI bars then immediately loaded by E-clip (Elitor gold metal alloy) retained overdentures (group 1) or T-clip (titanium housings with replaceable nylon clips) retained overdentures (group 2). Marginal bone loss was measured after 6 and 12 months of insertion. Patient satisfaction was evaluated using visual analogue scale (VAS) and oral health quality of life (QHRQoL) which was measured using Oral health impact profile (OHIP-14) after 12 months of insertion.
\end{abstract}

Results: For both groups, marginal bone loss significantly increased from 6 months to 12 months after insertion. Group 1 recorded significant higher marginal bone loss than group 2 at 6 and 12 months after insertion. Regarding VAS, Group 1 recorded significant lower scores (i.e., high patient satisfaction) of satisfaction of the dentures compared to natural teeth, the retention of the overdenture, the stability of the overdenture, and comfort with chewing with overdenture than group 2. Regarding OHIP-14, Group 1 recorded significant lower scores of comfort on eating, unsatisfaction with food, interruption of meal and difficulty in function well (i.e. high patient satisfaction) than group 2. No significant difference in other questions of VAS or OHIP-14 was noted between groups.

Conclusion: Within the limitations of this study, E-clip (gold alloy metal clip) was recommended for SFI bar when used for immediately loaded 4-implant assisted mandibular overdentures as it was associated with increased patient satisfaction compared to T-clip (nylon plastic clip). However, it was associated with increased marginal bone loss

KEY WORD: Implant overdenture, SFI bar, marginal bone loss, patient satisfaction.

\footnotetext{
* Associate Professor, MSA University

** Lecturer, Oral Radiology Department, Faculty of Dentistry, Fayoum University

*** Lecturer, Biomaterial Department, Faculty of Dentistry, Fayoum University, Egypt.
} 


\section{INTRODUCTION}

Improving the retention and stability of mandibular implant overdentures using two implants inserted in the canine regions are considered nowadays the minimum standard of care for edentulous patient ${ }^{1,2}$ However, 4- implant assisted mandibular overdentures are indicated in many situations such as sensitive mucosa, knife edge crest of the mandibular ridge, sharp mylohyoid ridge, opposing natural teeth for better load distribution ${ }^{3}$. Such overdentures reduce soft tissue support ${ }^{4}$, provide excellent retention and stability of the prothesis and reduce residual ridge resorption by elimination of denture rotation and loading of posterior mandibular ridge. ${ }^{5}$

The commonly used to design for 4-implant assisted overdentures is insertion of four implants in the interforaminal area of the mandible connected with cantilevered $\operatorname{bar}^{6,7}$. However, the use of cantilevers increases in stress transmission to the distal implants $^{8}$ and may induce prosthetic complications such as screw loosening and fracture of cantilevers 9 . Moreover, cantilevers usually not enough to extend support area posteriorly to obtain good masticatory efficiency ${ }^{10}$. Several authors reported the use of two implants anterior to the mental foramen and two implants posterior to the mental foramen when mandibular ridge anatomy permits and the connection of the implants with long bars ${ }^{10-13}$. Komiyama ${ }^{10}$ reported that insertion of the implants posterior to the mental foramina and the connection of these implants to the anterior implants with long bar improve patient satisfaction, enhance denture stability and retention. Furthermore, comfort and mastication are enhanced ${ }^{11}$ due to quadrilateral and wide implant distribution ${ }^{14,15}$. Elsyad, et al. ${ }^{12}$ reported that this design enhance masticatory function, electromyographic activity of masticatory muscles, maximum bite force and chewing efficiency of mandibular overdentures compared to 2 implant overdentures.

The advantages of bar attachments compared to unsplinted attachments include; load distribution between implants and reduction of nonaxial loads ${ }^{16,17}$, excellent horizontal and lateral prosthesis stability ${ }^{18}$, increased retention, lower incidence of prosthetic complications ${ }^{19}$ and ability to be used with non-parallel implants ${ }^{20}$. Bars also provide significant advantage when used with immediate loading of the implants as it reduces micromotions at bone to implant interface which improve osseointegration $^{21,22}$ and increase bone support area of the prosthesis ${ }^{14}$. However, bar attachments have several disadvantages such as complex laboratory procedures, increased costs, lack of passive $\mathrm{fit}^{23}$, the need of vertical restorative $\operatorname{space}^{24}$, and the complicated oral hygiene procedure ${ }^{25}$

Stress free-implant (SFI) bar was introduced by Cendres+Metaux SA company (Biel/Bienne, Switzerland) as a prefabricated round bar attachment that can be used with immediate loading of the implants with overdentures ${ }^{26}$ as it can be modified and adjusted to the implants chairside. This provides several advantages such as elimination of impression, no need to splint the transfers to obtain passive fit of the $\operatorname{bar}^{27}$, no soldering or welding and consequently no corrosion ${ }^{28}$. It saves time and can be used to splint immediate loaded implants. The bar is totally stress free and have a passive- $\mathrm{fit}^{27}$ as due to the joint nature of the implant adapters (abutments) as the bar is screwed passively in the adapters after adjustment of the bar. Moreover, this bar can be used with individual implant angulations up to $15^{\circ 29}$. The SFI bar composed of 2 or 4 ball joints that are screwed to implant adapters (similar to bar abutments) by screws and tube bars. The length of tube bar can be adjusted according to the distance between the implants. The bar has 2 types of female parts (clips). The first one is the E-clips (Elitor gold metal alloy) and the T-clips (titanium grade IV metal housings with replaceable nylon clips of different retention values) $)^{27}$.

Immediate loading protocol for overdentures have several advantages including reduction of 
patients visits, immediate restoration of mastication and aesthetics, improving patient satisfaction ${ }^{30}$. The evaluation of marginal bone loss around implants subjected to immediate loading protocol is very important to ensure long term success ${ }^{31}$. Moreover, patient-reported outcomes such as patient satisfaction and oral health-related quality of life (OHRQoL) is affected by prosthesis and attachment types $^{32}$. Patient satisfaction can also be evaluated through quantification of patients' opinion regarding the overdentures ${ }^{33}$. The effect of prostheses on quality of life is also a relatively recent research line. The Oral Health Impact Profile (OHIP), is a suitable means to assess OHRQoL during dental treatment ${ }^{34}$.

Reviewing the literature, there is lack of studies in the literature regarding the use of SFI bars on 4 implants. No studies were also concerned with evaluation of the outcomes of different types of clips used for this bar. Moreover, the effect of the material of clips of stress-free implant bars on marginal bone loss and patient satisfaction was not sufficiently investigated. Accordingly, the aim of this randomized trial was to evaluate marginal bone loss and patient satisfaction with gold alloy metal clip versus nylon plastic clips of stress-free implant (SFI) bar used for immediately loaded 4-implant assisted mandibular overdentures. The null hypothesis is that there will be no significant difference measured outcomes between the two clip materials.

\section{MATERIALS AND METHODS}

\section{Patient selection and study design}

Eight patients (4 men and 4 women, mean age $=57.5 \pm 4.6$ years) with completely edentulous maxillary and mandibular ridges were selected from the outpatient clinic of the Prosthodontic Department Faculty of Dentistry MSA university. The included patients were required to have; 1) unsatisfactory experience of retention and stability of mandibular conventional dentures and all participants required implant rehabilitation for stabilization of their conventional dentures, 2) adequate bone volume (height and width) anterior and posterior to the mental foramina which allow placement of implants of at least $11 \mathrm{~mm}$ in length $(3.5-4.0 \mathrm{~mm}$ in diameter according to ridge width) as verified by preoperative cone beam computerized tomography (CBCT), 3) sufficient restorative space (at least 15 $\mathrm{mm}$ between the occlusal plane and the mucosa) to allow inclusion of the bar with underlying hygienic space, clips, artificial teeth, and adequate thickness of denture base ${ }^{24}$. The exclusion criteria included patients with bone metabolic disorders such as diabetes mellitus, patients received radiotherapy or chemotherapy in the head region the last 2 years, bleeding disorders, and patients with bad habits such as smoking, bruxism and bad oral hygiene. A written informed consent was provided for all participants that explains the protocol, the steps and objectives of the study and each patient signed the consent. The protocol of the study was approved by the ethical committee of the Faculty of Dentistry MSA University (ETH 39).

For each participant, new upper and lower complete dentures were constructed with bilateral balanced occlusal concept and semi-anatomic acrylic teeth (Acrostone, Egypt). All patients were instructed to wear the dentures for at least one month to enhance neuromuscular adaptation. The patients were randomly assigned into two groups [4 patients (2males and 2 females) in each group]. Each participant was given a number. Randomization was performed using random numbers generated in Excel sheet to ensure equal distribution of gender between groups. Group 1 included 4 patients who received 4 implants connected with SFI bar and immediately loaded with E-clip (Elitor gold metal alloy) retained overdentures. Group 2 included 4 patients who received 4 implants connected with SFI bar and immediately loaded with T-clip (titanium housings with replaceable nylon clips) retained overdentures. 


\section{Surgical and prosthetic procedures}

For each participant, the mandibular denture was duplicated into heat cured acrylic resin, and Gutta percha markers were added at the polished surface of the duplicate dentures to convert to the duplicate dentures to radiographic template. For the preoperative assessment, a dual scan protocol was performed for each patient cone beam radiographic scanning was used (Scanora ${ }^{\circledR} 3 \mathrm{D}$ with AutoSwitchTM, Soredex, Helsinki, Finland). A CMOS flat panel detector with an isotropic voxel size of $133 \mathrm{Um}$, a focal spot size of $0.5 \mathrm{~mm}$, and a slice thickness of $1 \mathrm{~mm}$ was employed. The exposure conditions were $85 \mathrm{kVp}$ and $16 \mathrm{~mA}$, with a scanning period of 10 seconds and a pulsed exposure time of 3 seconds. The field of view measured $7 \mathrm{~cm}$ in height, $14.5 \mathrm{~cm}$ in breadth, and $10 \mathrm{~cm}$ in depth. Three laser light beams led the FOV adjustment to center the area of interest within the scanning field. The DICOM data set's primary reconstruction time was 2 minutes. One scan was performed while the patient wearing the radiographic template, and the other scan was performed for the template alone. The images from the DICOM data set were loaded into the OnDemand 3D software for secondary reconstruction and overlapping of the images were made using this 3-D image treatment planning software (OnDemand 3DTM software, version 1.0.9, Cybermed Inc., Korea).

For all patients, planning of implant position was performed at canine and first molar areas parallel to each other's after the evaluation of implant sites on the proximity to vital structures. The plan was used to construct custom tissue supported Stereolithographic surgical guide for each participant using prototyping technology (3D printing, In2Guide, Cybermed, USA). with 4 metal sleeves positioned over proposed implant sites.

Under local anesthesia, the Stereolithographic surgical guide was fixed to the mandibular bone using anchor pins while the patient bite in centric rubber base interocclusal record (Fig 1). Four implants (Neoss Ltd., Harrogate, England) were inserted according to the flapless surgical approach using the surgical guide and the universal surgical kit (In2Guide) supplied with the guide.

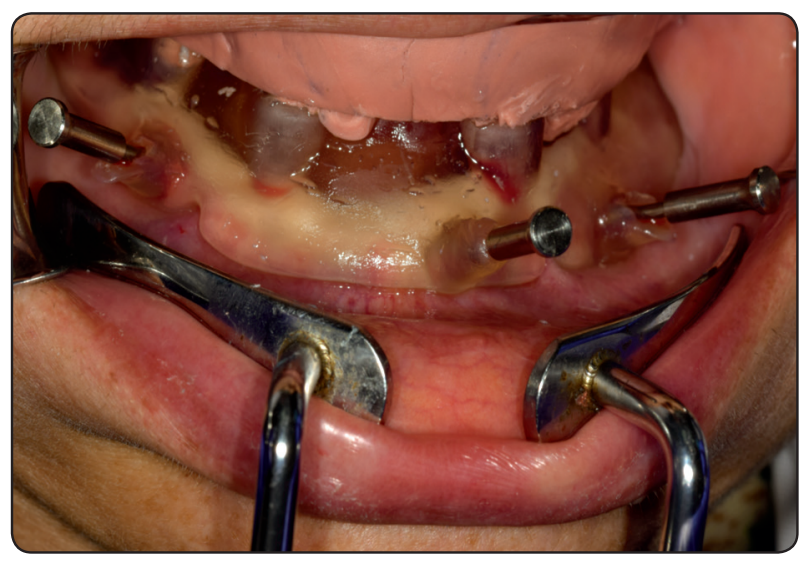

Fig. (1) Fixation of the guide to the mandibular bone using the rubber base centric interocclusal record .

Implant osteotomy preparation was made using successive drills of increasing diameters that fitted into the sleeves of the template. The implants were inserted at minimum $35 \mathrm{Ncm}$ torque to permit immediate loading of the implants ${ }^{35}$. In case of reduced bone density, under preparation of implant osteotomy was made by omitting the last drill to obtain sufficient implant stability. If $35 \mathrm{Ncm}$ torque was not obtained, the implants were submerged, the patient was excluded from the study and replaced by another patient. Directly after implant insertion, implant level open tray direct impression procedure was performed using a perforated stock tray over implant sites. The impression was made to produce a cast on which adjustment of the bar was made chairside to provide adequate visualization and reduce patient discomfort. Long impression posts were threaded to the implants, light consistency rubber base impression was loaded around the impression posts and the overall impression was made using putty material (Zhermack ${ }^{\circledR}$, Badia Polesine, Rovigo, Italy) loaded in the stock tray. Implant analogues were attached to the impression 
posts and the impression was poured using quick setting stone. On the cast, The SFI-Bar ${ }^{\circledR}$ (Cendres + Metaux, Biel/Bienne, Switzerland) implant adapters (abutments) were threaded to the implant analogues. The ball joint of the bar was fixed to the adapters, but the fixation screws were loosened to allow adjustment of the bar length. The tube bar gauge was attached to the bar and slide onto the pin of the ball joint until the joint can be fitted to the adapter and the retaining screws were retightened. The tube bar was sectioned using a metal disc and slide onto the pins of the ball joints and retightened tension-free. The procedure was repeated for the other 2 segments of the bar to complete adjustment of the total bar assembly (Fig 2). The implant adapters were screwed from the implant analogs and screwed to the implants in patient mouth with a torque wrench $(25 \mathrm{~N} / \mathrm{cm})$ after disinfection. The adjusted bar assembly was screwed to the adapters in patient mouth without tension (fig 3).

For both groups, 3 clips were used on the 3 bar segments (one clip on the bar segment between right canine and molar implants, one clip between right and left canine implants, and one clip between left canine and molar implants. For group 1, E-clips (Elitor gold metal alloy) were used and for group 2, T-clips (titanium grade IV metal housings) with red replaceable nylon clips (medium retention values) were used. The clips were positioned on the bar segments intraorally. Using a pressure indicating media (Fit Checker), the denture was sufficiently relieved over the bar and the clip using a cylindrical acrylic bur till no contact existed between the denture and the bar (fig 4).

The space under and around the bars was blocked out with wax. The gold metal alloy contained a T-shaped metal flange for mechanical retention with acrylic resin. The gold metal clip (group 1, Fig 5) and the housings with retentive clips (group 2) were picked up intraorally with self-cure acrylic resin to ensure passive fit (Fig 6).

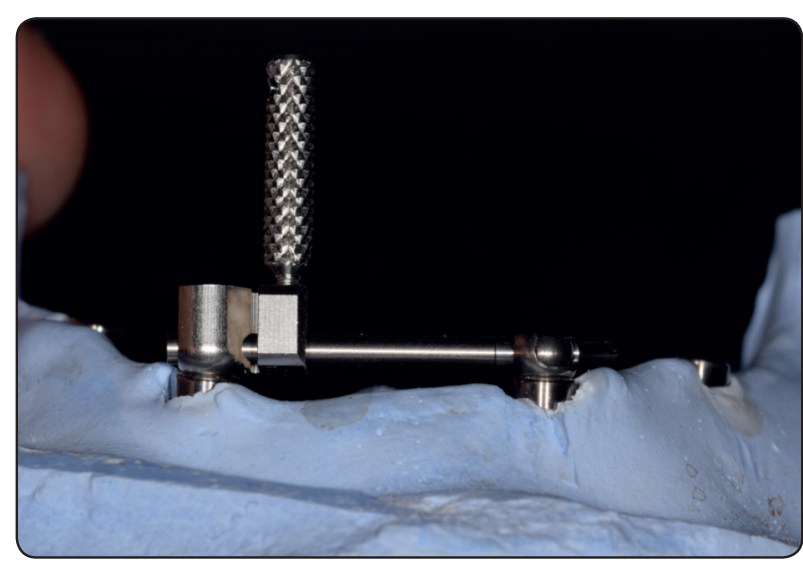

Fig (2) Adjustment of the SFI bar on the cast

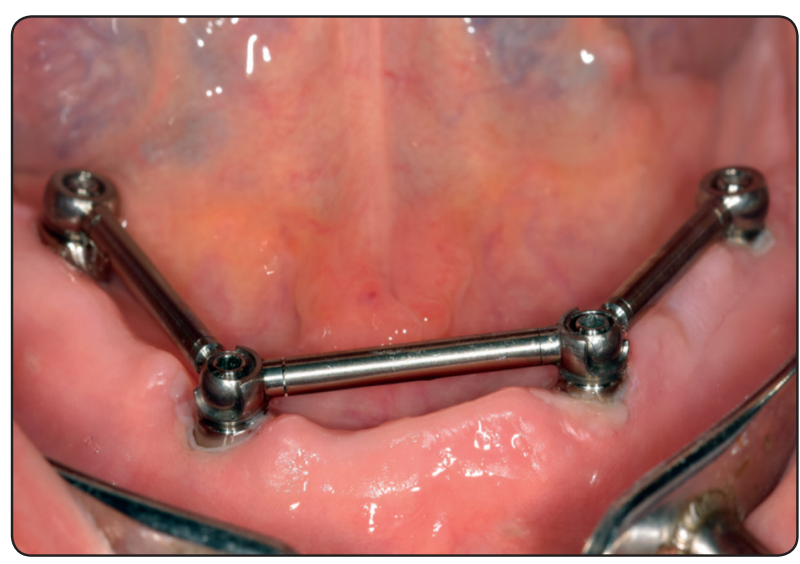

Fig. (3) The adjusted bar screwed to the implant adapters intraorally.

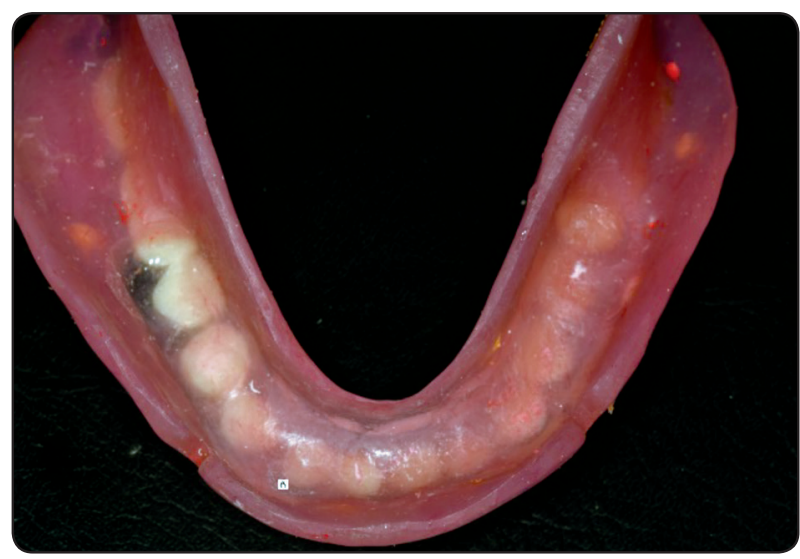

Fig. (4). Relief in the fitting surface of the overdentures over the bar 


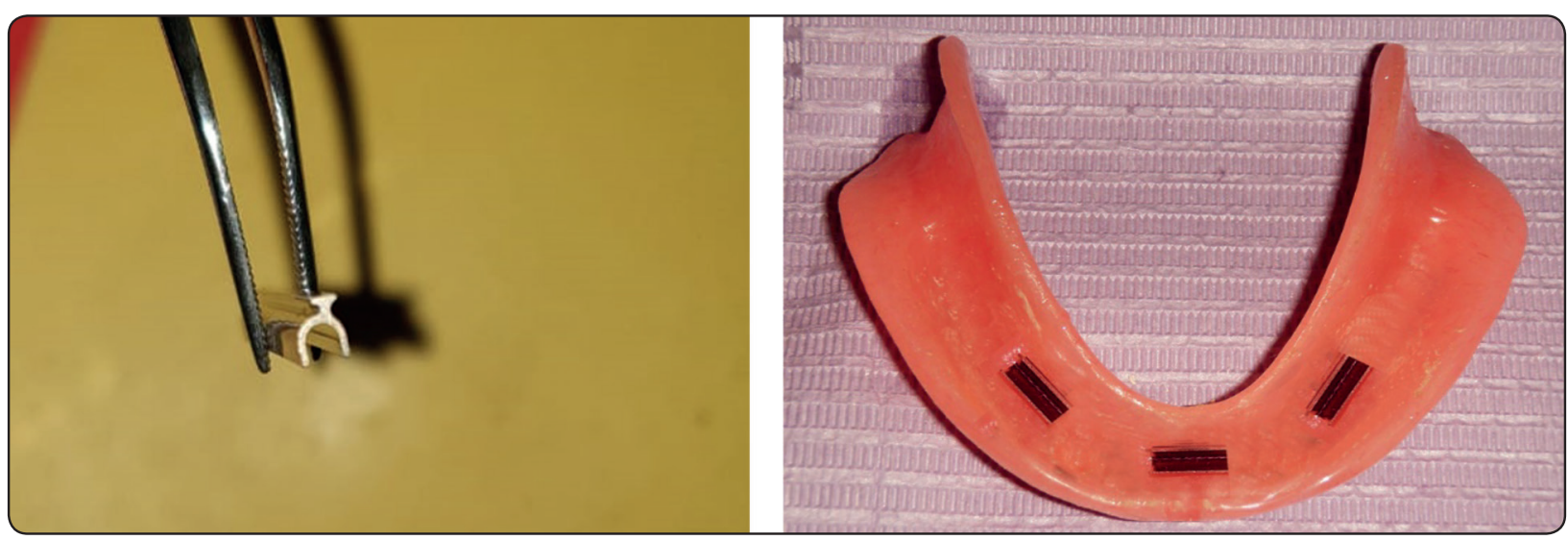

Fig. (5) Group 1; E-clip retained overdentures

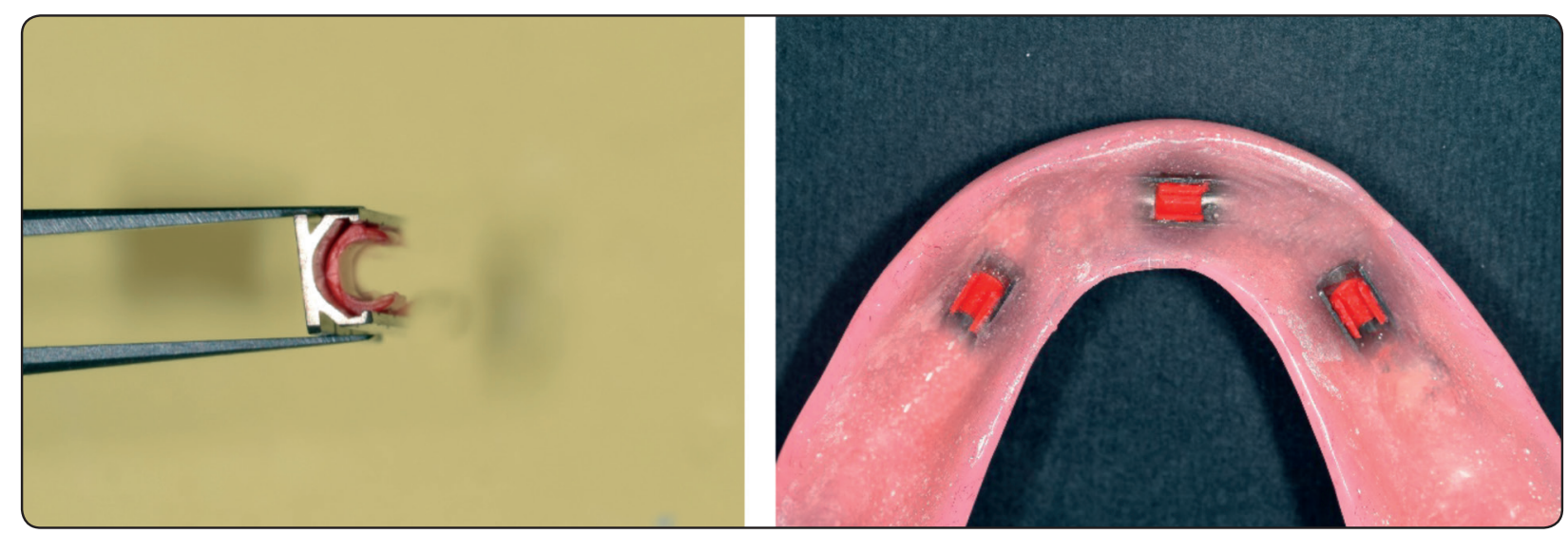

Fig. (6) Group 2; T-clip retained overdentures

The overdentures were delivered to the patients in the same day of implant placement with emphasis on oral hygiene instructions. The occlusion was refined using selective griding to ensure homogenous occlusal contact in centric and eccentric relation. Soft diet was prescribed for all participants and 2-weeks regular recall visits for adjustments were scheduled all over the study period. Postoperative medications included antibiotics (amoxicillin 625 $\mathrm{mg}+$ clavulanic acid $125 \mathrm{mg}$, Augmentin ${ }^{\circledR} 1 \mathrm{gm}$ ) for 6 days later. Anti-inflammatory medication (ibuprofen $\AA, 600 \mathrm{mg}$ ) was administered for 4 days postoperatively. Analgesics (Ketolac ${ }^{\circledR} 10 \mathrm{mg}$ ) were given on the day of surgery and postoperatively for the first 4 days. Chlorhexidine digluconate mouthwash was prescribed 3 times/day for one week.

\section{Study outcomes}

\section{Marginal bone loss}

Crestal bone height changes were measured using digital periapical radiographs (Digora, Soredex) taken by long cone paralleling technique. An interocclusal acrylic jig was used to fix the plastic film holder (Rinn, XCP bite blocks, Dentsply) between maxillary and mandibular teeth during subsequent film exposures to maintain a repeatable position of film implant distance and the 
cone implant distance for standardization. Using Digora ${ }^{\circledR}$ system (Soredex incorporation, Helsinki, Finland), crestal bone height was measured from implant platform (Point A) to first bone to implant contact (Point B, fig 7) ${ }^{36}$. To compensate for magnification errors, the actual implant length and width was compared to implant dimensions in the $\mathrm{x}$-ray to obtain the actual bone height changes in the $\mathrm{x}$-ray. Crestal bone height changes were measured at baseline (overdenture insertion), 6 and 12 months after insertion. Crestal bone loss was calculated by subtracting corresponding bone heights after 6 and 12 months from bone height at baseline. Measurements were made on both the mesial and distal aspects of each implant and the mean was subjected to statistical analysis.

\section{Patient satisfaction}

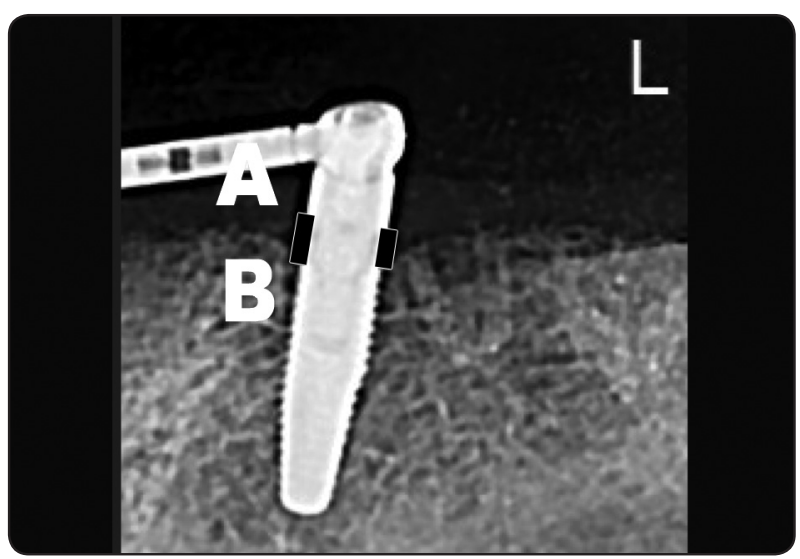

Fig. (7) Measurement of marginal bone height in peri-apical radiographs

Evaluation of patient satisfaction was performed using visual analog scale (VAS) and oral health-related quality of life (OHRQoL). Regarding visual analogue scale, subjects were asked to draw a vertical line anywhere across a horizontal one (on a scale from 0 to $100 \mathrm{~mm}$ ) at the point that best represented their perceptions ${ }^{37}$. Higher VAS scores indicate high satisfaction, and lower scores indicate low satisfaction. The questions of VAS include general satisfaction of prosthesis, satisfaction of prosthesis compared to natural teeth, prosthesis retention, prosthesis stability, prosthesis occlusion, prosthesis cleaning, speech with prosthesis, appearance of prosthesis, chewing with prothesis, prosthesis handling, sensation that prosthesis is a part of the patient, feeling of embarrassment. Oral health related quality of life was measured using oral health impact profile (OHIP-14) questions ${ }^{38}$. The OHIP contains 7 domains and each domain contain 2 questions. The domains are functional limitation (pronouncing sounds, and sense of taste), physical pain (painful aching, and comfort on eating), psychologic discomfort (self-consciousness, and feeling tense), physical disability (unsatisfactory diet, and interrupting meals), psychologic disability (difficult to relax, and embarrassing), social disability (irritability with people, and difficulty in jobs), and handicap (life in general, and inability to function). Participant responses to each question of OHIP (included in table 2) were never (1), hardly ever (2), occasionally (3), fairly often (4) and very often (5). Lower scores indicated higher satisfaction, vice versa. All questionnaires were translated and given in Arabic to all participants. VAS and OHIP-14 were measured after one year of overdenture insertion.

\section{Statistical analysis}

The data were analyzed using the SPSS statistical package version 22 (SPSS Inc., Chicago, IL, USA). The normality of data distribution was tested with Shapiro-Wilk test. The marginal bone loss data was parametric and presented by mean and standard deviation. Comparison of bone loss between 6 and 12 months was made using paired samples t-test and between groups was made using independent t-test. The VAS and OHIP-14 data were non-parametric and described by median, minimum and maximum. Comparison of VAS and OHIP-14 data between groups was made using Mann-Whitney test. P is significant if $<0.05$ at confidence interval $95 \%$. 


\section{RESULTS}

All patients attended regularly the follow-up visits without dropouts due to the short evaluation period. One implant failed in one patient in group 1 due to implant overloading, and no implant failures occurred in group 2 resulting in $93.75 \%$ and $100 \%$ implant survival rate for group 1 and group 2 respectively. The failed implant was associated with implant mobility without pus formation. The failed implant was removed, the bar was sectioned, and the overdenture was connected to the remaining implants. The study was completed according to the "intention to treat principal". Comparison of marginal bone loss between groups and between 6 and 12 months after insertion is presented in table 1. For both groups marginal bone loss significantly increased from 6 months to 12 months after insertion. Group 1 recorded significant higher marginal bone loss in group 2 at 6 and 12 months after insertion.

Comparison of VAS for groups after 12 months of denture insertion is presented in table 2. There was a significant difference between groups regarding the following questions: satisfaction compared to normal teeth, the retention of the overdenture, the stability of the overdenture, and comfort with chewing with overdenture. Group 1 recorded significant lower scores (i.e. high patient satisfaction) of satisfaction compared to normal teeth, the retention of the overdenture, the stability of the overdenture, and comfort with chewing with overdenture than group 2. No significant difference in satisfaction between groups was noted for general satisfaction, the occlusion of the overdenture, the cleanability of the overdenture, the phonetics of the overdenture, overdenture esthetics, ease of handling of overdenture, overdenture as apart of you, and embarrassment by overdentures

Comparison of Oral health related quality of life (OHIP-14) between groups 12 months of denture insertion is presented in table 3 . There was a significant difference between groups regarding the following questions: Comfort on eating, unsatisfaction with food, interruption of meal and difficulty in function well. Group 1 recorded significant lower scores of comfort on eating, unsatisfaction with food, interruption of meal and difficulty in function well (i.e. high patient satisfaction) than group 2. No significant difference in satisfaction between groups was noted for pronunciation of sound, sensation of taste, pain or ache, Self-consciousness, sensation of tense, unable to relax, embarrassment, irritation with others, difficult doing job, and life generally

TABLE (1) Comparison of marginal bone loss between groups and between 6 and 12 months after insertion

\begin{tabular}{lccc}
\hline & $\mathbf{6}$ months after insertion & $\mathbf{1 2}$ months after insertion & Paired samples t-test P-value \\
\hline $\begin{array}{l}\text { Group 1 (E-clip retained } \\
\text { overdentures) }\end{array}$ & $.82 \pm .24$ & $1.13 \pm .35$ & $.002^{*}$ \\
$\begin{array}{l}\text { Group 2 (T-clip retained } \\
\text { overdentures) }\end{array}$ & $.62 \pm .21$ & $.87 \pm .28$ & $.004^{*}$ \\
$\begin{array}{l}\text { Independent samples t-test } \\
\text { P value }\end{array}$ & $.003^{*}$ & $.001 *$ & \\
\hline
\end{tabular}

*P is significant at $.05 \%$ 
TABLE (2): Comparison of VAS for groups after 12 months of denture insertion.

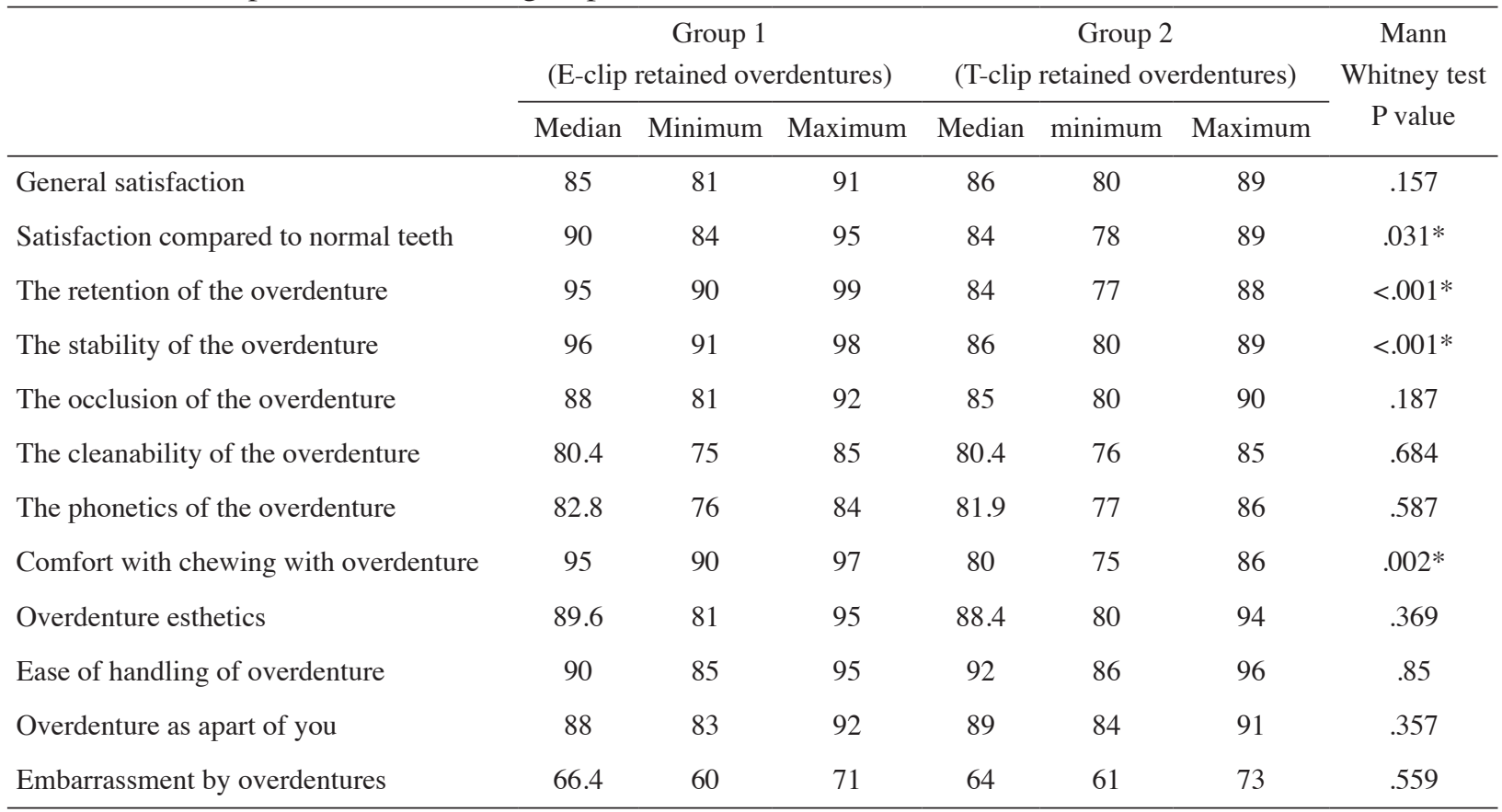

\section{*P is significant at $.05 \%$}

TABLE (3): Comparison of Oral health related quality of life (OHIP-14) between groups 12 months of denture insertion

\begin{tabular}{|c|c|c|c|c|c|c|c|}
\hline \multirow[b]{2}{*}{ Question } & \multicolumn{3}{|c|}{$\begin{array}{c}\text { Group } 1 \\
\text { (E-clip retained overdentures) }\end{array}$} & \multicolumn{3}{|c|}{$\begin{array}{c}\text { Group } 2 \\
\text { (T-clip retained overdentures) }\end{array}$} & \multirow{2}{*}{$\begin{array}{c}\text { Mann Whitney test } \\
\text { P value }\end{array}$} \\
\hline & Median & Minimum & Maximum & Median & Minimum & Maximum & \\
\hline Pronunciation of sound & 2.8 & 1.9 & 3.2 & 2.9 & 1.8 & 3.1 & .351 \\
\hline Sensation of taste & 2.5 & 2.1 & 2.9 & 2.6 & 2.2 & 2.9 & .147 \\
\hline Pain or ache & 1.9 & 1.5 & 2.5 & 1.8 & 1.4 & 2.4 & .254 \\
\hline Comfort on eating & 1.5 & 1.1 & 1.8 & 2.5 & 2.1 & 2.9 & $.004 *$ \\
\hline Self-consciousness & 2.7 & 2.3 & 3.1 & 2.8 & 2.2 & 3.2 & .321 \\
\hline Sensation of tense & 2.1 & 1.7 & 2.4 & 2.8 & 1.8 & 2.5 & .358 \\
\hline Unsatisfaction with food & 1.3 & 1.0 & 1.5 & 2.0 & 2.3 & 1.6 & $.005 *$ \\
\hline Interruption of meal & 1.9 & 1.6 & 2.3 & 2.5 & 2.1 & 2.9 & $.002 *$ \\
\hline Unable to relax & 2.0 & 1.6 & 2.2 & 2.2 & 1.6 & 2.3 & .451 \\
\hline Embarrassed & 1.8 & 1.5 & 2.3 & 1.9 & 1.4 & 2.4 & .159 \\
\hline Irritation with others & 1.5 & 1.2 & 1.7 & 1.6 & 1.3 & 1.8 & .528 \\
\hline Difficult doing job & 1.6 & 1.2 & 1.9 & 1.7 & 1.3 & 2.0 & .751 \\
\hline Life generally & 1.9 & 1.6 & 2.3 & 2.1 & 1.8 & 2.4 & .354 \\
\hline Difficulty in function well & 1.8 & 1.4 & 2.2 & 2.5 & 2.1 & 2.9 & $.003^{*}$ \\
\hline
\end{tabular}




\section{DISCUSSION}

The most used types of clips that retained overdentures to the bars are metallic and plastic clips. The metal clips can be adjusted as retention decreased and are less liable to wear. On the other hand, plastic clips can be easily replaced if retention decreased and are less expensive than metal clips. However, such plastic clips cannot be adjusted ${ }^{39}$. Therefore, it is important to study the effect of clip material on the clinical outcomes of immediately loaded implants with bar overdentures particularly with the new bar designs such as the readymade stress-free implant bar. In this study, the red plastic clips (medium retention) were selected for SFI bar to be similar to the retention values of gold metal clips based on a previous study $^{27}$ in which the authors compared these 2 types of clips for SFI bar. The null hypothesis was rejected as significant difference in marginal bone loss and patients' satisfaction was noted between E-clips and T-clips of SFI bar.

The implant survival rates were $93.75 \%$ and $100 \%$ implant survival rate for group 1 and group 2 respectively. The reduced survival rate with group 1 may be attributed to the increased retention of the gold metal clips which may transfer more load to the implants during the healing process as immediate loading protocol was followed. The excessive micromotion between the implant and the peri-implant bone can be a compromising factor to osseointegration $^{40}$. On the other hand, the resiliency of the plastic clips in group 2 may contribute to reduction of force transmission to the implants, consequently no implant failures occurred.

For both groups, the mean marginal bone loss for all implant surfaces did not exceed $1 \mathrm{~mm}$ after one year. This amount of marginal bone loss is located in the normal range that was reported in earlier investigations ( less than $1.2 \mathrm{~mm}$ in the first year) ${ }^{41}$. This could be attributed to the high initial stability of the implants (due to the high bone density of the mandibular bone). Another reason of reduction of marginal bone loss is the splinting effect of the bar which distribute forces to large area providing optimal support and wide load distribution and reduce micromotion at bone to implant interface ${ }^{21}$, ${ }^{22}$. Furthermore, the passive seating of the SFI bar to the abutments reduce or eliminate stress transmitted to the implants ${ }^{27}$ and could be responsible also for reduction of marginal bone loss values.

For both groups marginal bone loss significantly increased from 6 months to 12 months after insertion. This time dependent bone loss is usually occur as a result of the healing, bone maturation and bone reaction to increased load ${ }^{42}$. Moreover, the immediate loading of the implants with overdentures may increase implant micromotions and could be responsible for increased bone resorption with time in both groups ${ }^{40}$. Group 1 recorded significant higher marginal bone loss in group 2 at 6 and 12 months after insertion. This may be due to gold metal clips were associated with increased retention than nylon plastic clips as confirmed by the results of patient satisfaction in this study. This increased retention may transfer more micromotion to the implant in the critical healing period and could be responsible for increased bone loss in group 1 . The increased retention caused an increase in bending moments during denture removal. These bending moments may enhance stress concentrations that may exceed the physiologic limit of bone, leading to bone resorption ${ }^{43}$. The increased peri-implant stress with gold metal clips in group 1 was in line with the results of Tanoue et al. ${ }^{44}$ who studied the effect of clip material for bar attachments on the stresses applied around implants supporting maxillary overdentures using finite element analysis. They found increased peri-implants stresses around the metal clips than plastic clips. On the other hand, the resiliency of nylon plastic clips in group 2 may act as a cushion and could contribute to reduction of stress transmission to the implants, and consequently reduction of marginal bone loss. Similarly, dos Santos et al..$^{45}$ found that plastic clips used for round bars reduced stress transmission to the peri-implant bone compared to gold clips. Therefore, in clinical 
setting, for the attachment to be valid on long term, it should provide adequate retention with reduction of stress transmission to the implant during denture removal $^{46}$.

Group 1 recorded high patient satisfaction scores of satisfactions compared to normal teeth, the retention of the overdenture, the stability of the overdenture, and comfort with chewing with overdenture than group 2. This could be attributed to the increase retention and stability of the metal gold clips (E-clips) compared to plastic (T-clips) clips. Similarly, Wei et al. ${ }^{27}$ found that the mean retentive force of the E-clips for SFI bar increased as the number of dislodging cycles increased, while the mean retention forces for the T-clips remained steady or decreased after repeated insertion and removals. They recommended adjustment from time to time to reduce retention forces of gold metal clips. They also recommend replacement of plastic clips after 2 years of clinical use due to wear and deformation of the clips. The increased retention of the E-clips may be attributed to the tribologic interaction of metalto-metal contacts. The friction between the titanium round bar and the metal gold clip (E-clip) in group 1 may increase the roughness during denture insertion and removal ${ }^{29}$ which result in increased retention forces ${ }^{47}$. In contrast, the replaceable plastic nylon insert of the T-clips are subjected to increased wear, plastic deformation of the inserts and retention loss compared to the metal gold clips of the SFI bar after repeated insertions and removals ${ }^{27}$. It was reported that polymeric (plastic, and nylon) components of attachments are more prone to wear than metallic components $^{48,49}$. However, it should be noted that activation or replacement of the metal or plastic clips in both groups was not performed objectively or subjectively in this study to avoid introduction of a variable that could significantly affect the accuracy of the results.

The increased retention and stability of gold metal clips compared to plastic clips was in agreement with Savabi, et al. ${ }^{50}$ who found that cantilevered Dolder bar with 3 metal clips recorded in- creased retention and stability compared to Hader bar with 3 pink plastic clips in both the vertical and postero-anterior directions. In contrast, Botega et $\mathrm{al}^{51}$, found that Hader bar with plastic clips had significantly higher initial and final retention values than Dolder bar with metal clips. The difference could be attributed to the cross section of the metal bar in the 2 studies. In our study, the titanium bar has round cross section and the metal gold clip has round cross-section that contact the bar evenly without intervening space. However, the Dolder bar in Botega study has Oval cross section that contact the $\mathrm{u}$-shaped titanium clips at the sides only. Therefore, the retention of the Dolder bar is lower than Hader bar in Botega study.

The increased retention and stability of the Eclip (gold metal clip) compared to T-clip (plastic clip) could be responsible for increased patient satisfactions compared to normal teeth. Moreover, the dentures are retained and stabilized well during mastication, thus patient comfort with chewing with overdentures are increased, patient un-satisfaction with food decreased, interruption of meal and difficulty in function well are decreased in group 1 than group 2. It has been reported that the degree of stability and retention of implant overdentures may improve masticatory efficiency and muscle activity $^{52,53}$. A good muscle activity is needed for proper chewing movements in order to cut or comminute the food $^{54}$. Therefore, increased retention and stability of overdentures in group 1 could improve maximum bite force and masticatory efficiency, increase patient satisfaction and reduce pain during mastication $^{52,53}$

The limitations of the study included the small patient number and the short evaluation period. The effect of clip activation or replacement if retention decreased was also not evaluated. Therefore, a future clinical study with sufficient sample size and long follow up period is recommended to ensure the finding of this study. Moreover, an objective measurement of retention forces of both types of clips in patient mouth is recommended. 


\section{CONCLUSION}

Within the limitations of this study, E-clip (gold alloy metal clip) was recommended for SFI bar when used for immediately loaded 4-implant assisted mandibular overdentures as it was associated with increased patient satisfaction compared to T-clip (nylon plastic clip). However, it was associated with increased marginal bone loss

\section{REFERENCES}

1. Feine JS, Carlsson GE, Awad MA, Chehade A, Duncan WJ, Gizani S et al. The McGill consensus statement on overdentures. Mandibular two-implant overdentures as first choice standard of care for edentulous patients. Gerodontology. 2002;19:3-4.

2. Thomason JM, Feine J, Exley C, Moynihan P, Muller F, Naert I et al. Mandibular two implant-supported overdentures as the first choice standard of care for edentulous patients--the York Consensus Statement. Br Dent J. 2009;207:185-6.

3. Mericske-Stern RD, Taylor TD, Belser U. Management of the edentulous patient. Clin Oral Implants Res. 2000;11 Suppl 1:108-25.

4. Cordaro L, di Torresanto VM, Petricevic N, Jornet PR, Torsello F. Single unit attachments improve peri-implant soft tissue conditions in mandibular overdentures supported by four implants. Clin Oral Implants Res. 2013;24:536-42.

5. de Jong MH, Wright PS, Meijer HJ, Tymstra N. Posterior mandibular residual ridge resorption in patients with overdentures supported by two or four endosseous implants in a 10-year prospective comparative study. Int J Oral Maxillofac Implants. 2010;25:1168-74.

6. Wismeijer D, Van Waas MA, Vermeeren JI, Mulder J, Kalk W. Patient satisfaction with implant-supported mandibular overdentures. A comparison of three treatment strategies with ITI-dental implants. Int J Oral Maxillofac Surg. 1997;26:263-7.

7. Abd El-Dayem MA, Assad AS, Abdel-Ghany MM. The effect of different mandibular dentures on antagonistic maxillary ridge. Implant Dent. 2007;16:421-9.

8. Sadowsky SJ, Caputo AA. Effect of anchorage systems and extension base contact on load transfer with mandibular implant-retained overdentures. J Prosthet Dent. 2000; 84:327-34.
9. Katsoulis J, Walchli J, Kobel S, Gholami H, MericskeStern R. Complications with computer-aided designed/ computer-assisted manufactured titanium and soldered gold bars for mandibular implant-overdentures: short-term observations. Clin Implant Dent Relat Res. 2015;17 Suppl 1:e75-85.

10. Komiyama Y. The interface between surgery and prosthodontics in implant dentistry Proceedings of the Third International Congress on Tissue Integration in Oral and Maxillofacial Reconstruction, Nagoya, Japan. 1996: 45-9.

11. Tang L, Lund JP, Tache R, Clokie CM, Feine JS. A withinsubject comparison of mandibular long-bar and hybrid implant-supported prostheses: psychometric evaluation and patient preference. J Dent Res. 1997;76:1675-83.

12. Elsyad MA, Hegazy SA, Hammouda NI, Al-Tonbary GY, Habib AA. Chewing efficiency and electromyographic activity of masseter muscle with three designs of implantsupported mandibular overdentures. A cross-over study. Clin Oral Implants Res. 2014;25:742-8.

13. ELsyad MA, Elsaadawy MG, Abdou AM, Habib AA. Effect of different implant positions on strain developed around four implants supporting a mandibular overdenture with rigid telescopic copings. Quintessence Int. 2013;44: 679-86.

14. Caruso G, Cattaneo A. Removable prosthesis supported by implants according to the Cagliari modified conometry technique: case report. Int J Periodontics Restorative Dent. 2007;27:259-65

15. Moll D, Yildirim M, Spiekermann H, Wolfart S. Telescopic crown-retained removable partial dentures on teeth and implants: An 8- to 9-year prospective randomized clinical trial. Clin Oral Implants Res. 2012.

16. Mericske-Stern R, Piotti M, Sirtes G. 3-D in vivo force measurements on mandibular implants supporting overdentures. A comparative study. Clin Oral Implants Res. 1996;7:387-96.

17. Misch CE, Wang HL, Misch CM, Sharawy M, Lemons J, Judy KW. Rationale for the application of immediate load in implant dentistry: part II. Implant Dent. 2004;13:310-21.

18. Spiekermann H. Implantology. In: Rateitschak, K.H. \& Wolf, H.F., eds. Color Atlas of Dental Medicine. New York: Thieme Medical Publishers. 1995:164.

19. Naert I, Gizani S, Vuylsteke M, Van Steenberghe D. A 5-year prospective randomized clinical trial on the 
influence of splinted and unsplinted oral implants retaining a mandibular overdenture: prosthetic aspects and patient satisfaction. J Oral Rehabil. 1999;26:195-202.

20. Carpentieri JR. Clinical protocol for an overdenture bar prosthesis fabricated with $\mathrm{CAD} / \mathrm{CAM}$ technology. Pract Proced Aesthet Dent. 2004;16:755-7.

21. Alfadda SA, Attard NJ, David LA. Five-year clinical results of immediately loaded dental implants using mandibular overdentures. Int J Prosthodont. 2009;22:368-73.

22. Lorenzoni M, Pertl C, Zhang K, Wegscheider WA. Inpatient comparison of immediately loaded and non-loaded implants within 6 months. Clin Oral Implants Res. 2003;14:273-9.

23. Barbi FC, Camarini ET, Silva RS, Endo EH, Pereira JR. Comparative analysis of different joining techniques to improve the passive fit of cobalt-chromium superstructures. J Prosthet Dent. 2012;108:377-85.

24. Ahuja S, Cagna DR. Defining available restorative space for implant overdentures. J Prosthet Dent. 2010; 104: 133-6.

25. Efvinol. B, Jorgeusen. D. Prosthetic for elderly. Quintessence, Publication Co. Inc.Chicago. . 1999:P233.

26. Kim HY, Kim RJ, Qadeer S, Jeong CM, Shin SW, Huh JB. Immediate loading on mandibular edentulous patient with SFI Bar (R) overdenture. The journal of advanced prosthodontics. 2011;3:47-50.

27. Wei L, Ma Q, Qin X, Pan S. In Vitro Cyclic Dislodging Test on Retentive Force of Two Types of Female Parts of SFI-Bar. The International journal of prosthodontics. 2016; 29:293-5.

28. Ha SR, Kim SH, Song SI, Hong ST, Kim GY. Implantsupported overdenture with prefabricated bar attachment system in mandibular edentulous patient. The journal of advanced prosthodontics. 2012;4:254-8.

29. Kobayashi M, Srinivasan M, Ammann P, Perriard J, Ohkubo C, Muller F et al. Effects of in vitro cyclic dislodging on retentive force and removal torque of three overdenture attachment systems. Clin Oral Implants Res. 2014; 25:426-34.

30. Chiapasco M, Gatti C. Implant-retained mandibular overdentures with immediate loading: a 3- to 8-year prospective study on 328 implants. Clin Implant Dent Relat Res. 2003;5:29-38.
31. De Bruyn H, Vandeweghe S, Ruyffelaert C, Cosyn J, Sennerby L. Radiographic evaluation of modern oral implants with emphasis on crestal bone level and relevance to peri-implant health. Periodontol 2000. 2013;62:256-70.

32. Feine JS, Awad MA, Lund JP. The impact of patient preference on the design and interpretation of clinical trials. Community Dent Oral Epidemiol. 1998;26:70-4.

33. ELsyad MA, Elgamal M, Mohammed Askar O, Youssef AlTonbary G. Patient satisfaction and oral health-related quality of life (OHRQoL) of conventional denture, fixed prosthesis and milled bar overdenture for All-on-4 implant rehabilitation. A crossover study. Clin Oral Implants Res. 2019.

34. Slade GD. Derivation and validation of a short-form oral health impact profile. Community Dent Oral Epidemiol. 1997;25:284-90.

35. Sannino G, Bollero P, Barlattani A, Gherlone E. A Retrospective 2-Year Clinical Study of Immediate Prosthetic Rehabilitation of Edentulous Jaws with Four Implants and Prefabricated Bars. J Prosthodont. 2017;26:387-94.

36. Canullo L, Fedele GR, Iannello G, Jepsen S. Platform switching and marginal bone-level alterations: the results of a randomized-controlled trial. Clin Oral Implants Res. 2010;21:115-21.

37. Awad MA, Feine JS. Measuring patient satisfaction with mandibular prostheses. Community Dent Oral Epidemiol. 1998;26:400-5.

38. Slade GD, Spencer AJ. Development and evaluation of the Oral Health Impact Profile. Community Dent Health. 1994;11:3-11.

39. Walton JN, Ruse ND. In vitro changes in clips and bars used to retain implant overdentures. J Prosthet Dent. 1995;74:482-6.

40. De Smet E, Duyck J, Vander Sloten J, Jacobs R, Naert I. Timing of loading--immediate, early, or delayed--in the outcome of implants in the edentulous mandible: a prospective clinical trial. Int $\mathrm{J}$ Oral Maxillofac Implants. 2007;22:580-94.

41. Albrektsson T, Zarb G, Worthington P, Eriksson AR. The long-term efficacy of currently used dental implants: a review and proposed criteria of success. Int J Oral Maxillofac Implants. 1986;1:11-25.

42. Hekimoglu C, Anil N, Cehreli MC. Analysis of strain around endosseous dental implants opposing natural teeth or implants. J Prosthet Dent. 2004;92:441-6. 
43. Akca K, Iplikcioglu H. Finite element stress analysis of the influence of staggered versus straight placement of dental implants. Int J Oral Maxillofac Implants. 2001; 16:722-30.

44. Tanoue M, Kanazawa M, Takeshita S, Minakuchi S. Effects of clip materials on stress distribution to maxillary implant overdentures with bar attachments. J Prosthet Dent. 2016;115:283-9.

45. dos Santos MB, Bacchi A, Correr-Sobrinho L, Consani RL. The influence of clip material and cross sections of the bar framework associated with vertical misfit on stress distribution in implant-retained overdentures. Int J Prosthodont. 2014;27:26-32.

46. Yang TC, Maeda Y, Gonda T, Kotecha S. Attachment systems for implant overdenture: influence of implant inclination on retentive and lateral forces. Clin Oral Implants Res. 2011;22:1315-9.

47. Pigozzo MN, Mesquita MF, Henriques GE, Vaz LG. The service life of implant-retained overdenture attachment systems. J Prosthet Dent. 2009;102:74-80.

48. Fromentin O, Picard B, Tavernier B. In vitro study of the retention and mechanical fatigue behavior of four implant overdenture stud-type attachments. Pract Periodontics Aesthet Dent. 1999;11:391-7; quiz 8.

49. Gamborena JI, Hazelton LR, NaBadalung D, Brudvik J. Retention of ERA direct overdenture attachments before and after fatigue loading. Int J Prosthodont. 1997;10:123-30.

50. Savabi O, Nejatidanesh F, Yordshahian F. Retention of implant-supported overdenture with bar/clip and stud attachment designs. J Oral Implantol. 2013;39:140-7.

51. Botega DM, Mesquita MF, Henriques GE, Vaz LG. Retention force and fatigue strength of overdenture attachment systems. J Oral Rehabil. 2004;31:884-9.

52. Van der Bilt A, Engelen L, Pereira L, Van der Glas H, Abbink J. Oral physiology and mastication. Physiol Behav. 2006;89:22-7.

53. van Kampen FM, van der Bilt A, Cune MS, FontijnTekamp FA, Bosman F. Masticatory function with implantsupported overdentures. J Dent Res. 2004;83:708-11.

54. ELsyad MA, Ibrahim AE, Nawar NHH, Belal TM. Electromyographic Connectivity of Masseter Muscle with Different Retentive Attachments for Implant Overdentures in Patients with Atrophied Mandibular Ridges: A Crossover Study. Int J Oral Maxillofac Implants. 2019;34:1213-22. 